\title{
Allergic Rhinitis: Impact and Common Triggers in Primary School Children in Calabar, Nigeria
}

\author{
Francis $\mathrm{PM}^{1}$, Adekanye $\mathrm{AG}^{1 *}$, Umana $\mathrm{AN}^{1}$, Omotoso $\mathrm{AJ}^{2}, \mathrm{MgbeRB}^{1}$ and NwaorguOGB \\ ${ }^{1}$ Department of Otorhinolaryngology, University of Calabar, Nigeria \\ ${ }^{2}$ Department of Pathology, University of Calabar, Nigeria \\ ${ }^{3}$ Department of Otorhinolaryngology, University College Hospital, Nigeria
}

Submission: July 16, 2019; Published: July 30, 2019

*Corresponding author: Adekanye AG, Department of Otorhinolaryngology, University of Calabar, Nigeria

\section{Abstract}

Background: The impact of allergic rhinitis is tremendous; severity of allergic rhinitis ranges from mild to seriously debilitating. School children with this disease often suffer from both emotional and behavioral effects. Symptoms like fatigue, sleep disturbance, learning and attention problems as well as absenteeism and presenteeism (present but with impaired function) at school are considerably great. Triggers (allergens) of allergic rhinitis are many and vary from one locality to another. These allergens include food, pollens, and pets; strong odor, smoke, cold weather, dust and history of atopy.

Objective: To assess the impact and triggers of allergic rhinitis in primary school children in Calabar.

Material and Methods: A prospective, cross - sectional community-based study of primary school children in ten (10) randomly selected Government primary schools in Calabar. Children between 6 to 11years were recruited and evaluated for symptoms and signs of AR. Multi - stage sampling technique were used. Written informed consent was obtained from parents / guardians and assent from children. Adapted structured questionnaire was distributed and detailed Ear, Nose and Throat examination done.

Results: Of the three hundred and fifty - four participants who completed the study, 176 (50.6\%) were males and 175 (49.4\%) females. One hundred and sixty - seven subjects (94.4\%) were diagnosed with AR using nasal smear eosinophil count. In the study group, the most common symptom was rhinorrhea (runny nose) 163 (92.1\%), excessive sneezing162 (91.5\%) and nasal itching / itching eyes 158 (89.3\%), each with a $\mathrm{p}$ - value of $\leq 0.0001$. The impacts of symptoms of AR among the subjects in our study revealed that $98(55 \%)$ had sleep disturbance, interference with daily activities and playing or socialization $40(23.0 \%)$ and disruption in school attendance $39(22.0 \%)$. The commonest allergen was dust, accounting for $68 \%$; followed by cold weather (60\%) and positive family history of atopy ( $51 \%)$.

Conclusion: The important impacts experienced by the group studied showed the lack of a good night sleep, interference with outdoor activities, as well as absenteeism. Common precipitating factors in these children were dust, cold weather and family history of atopy. Overall, the disease impacts significantly on their quality of life.

Keywords: Allergic Rhinitis; Impact; Triggers; Children.

\section{Introduction}

Allergic rhinitis (AR) and its co morbidities like asthma, sinusitis, and otitis media with effusion have a profound impact on the daily lives of children. Many of the problems go completely unnoticed as children often fail to share them at home or at school. It may result in day - time fatigue, as well as sleeplessness and impairment of cognition and memory. This may significantly affect the learning process and thus impacts on school performance and all these aspects upset the family [1]. Children with AR are often embarrassed in school and have decreased social interaction that significantly hampers the process of learning and school performance [2]. The adverse effects of some medications used for treatment often compound these problems [3]. The risk factors of allergic rhinitis include the following dust, moulds, weather changes, pollen, pets and exposure to tobacco smoking.

\section{Materials and Methods}

Ethical permission for this study was obtained from Institution Review Board, University of Calabar Teaching Hospital. Written approval was obtained from the Ministry of Education Calabar and the principals of the schools. Also, written informed consent was obtained from the parents / caregivers and assent from the pupils before the commencement of this work. This study was a prospective, cross - sectional community based study of primary school children in 10 randomly selected 
Government schools in Calabar over a period of fourteen weeks. The sample size used for the study $(\mathrm{n}=180)$ was estimated using the Leslie Kish formula and prevalence of $12 \%$ [4]. Five (5) schools were randomly selected from each Local Government Area. Balloting method was used to select one arm of each class. Multi - stage stratified sampling technique was used to select the participants. Thirty-six children were drawn from each school, giving a total of 360 participants. Those with two or more symptoms of AR were subjects. Others without the symptoms constituted the controls [1]. The control group were matched for age and sex with the subjects.

Potential participants were identified and adapted structured questionnaire was distributed through the class teachers. These were taken home for a period of two days, after which they returned the completed and signed questionnaire. Nasal smear specimen was taken with sterile disposable nasal probes (orange stick with sterile cotton wool), with the researcher face masked and hand gloved. For each nasal cavity, a probe was run along the medial surface of the inferior turbinate about 2 -3 times. Alternatively, for those who were not able to tolerate the little discomfort, sterile plastic films were given to them to blow their nose gently onto and the secretions collected using the disposable nasal probes [5]. The specimen was smeared on a clear glass slide. Two separate slides were produced, one from each nasal cavity. The same was done for the control group. These were air dried and immediately fixed with 95\% alcohol. Staining was done using the modified Wright's Giemsa stain method. The consultant pathologist single examined slides under light microscopy within one month - blinded to the clinical status of the participants. Eosinophils were viewed at high power oil immersion $x 1000$. A finding of $>5$ eosinophils in 3 -5 fields of view or a single finding of 20 to 30 cells was considered positive for nasal eosinophilia [6]. The grading of the nasal smear eosinophilia was done according to Abhey et al [7-9] using semi - quantitative scale. Applying strict aseptic precautions, venous blood samples were taken by venepuncture from all consented participants.

Each sample (3mls) of blood was collected into Ethylene Diamine Tetra Acetic Acid (EDTA) anticoagulant bottles. These were examined for absolute eosinophil count (AEC). Blood eosinophilia was considered if eosinophil > 600cells per micro - liter was present. Graded as mild (600 -1500 cells), moderate (1500 -5000cells) and severe ( $>5000$ cells) per micro-liter $[5,10$ 12]. The difficulties of blood sample collection were overcome by the presence and co - operations of the schoolteachers. Similarly, through advocacy via the Parents Teachers Associations (PTAs) the cultural issues of using blood for rituals and money largely overcome. Furthermore, stool samples were collected from all consented participants by distributing universal sample containers to them and collecting the samples the next day. These were immediately transported to the laboratory for microscopy and identification of intestinal parasites. Diagnosis of AR was based on finding of 2 or more symptoms. Statistical analysis of the obtained data was done using the statistical package for social sciences (SPSS) software version 17. Level of significance was set at $\mathrm{p}$-value of less than 0.05 at $95 \%$ confidence intervals.

Table 1: Distribution of allergic rhinitis symptoms of study participants.

\begin{tabular}{|c|c|c|c|c|c|}
\hline Symptoms & Responses & Subjects (\%) & Controls N (\%) & $\mathbf{X}^{2}$ & p-value \\
\hline \multirow{2}{*}{ Nasal congestion } & Yes & $149(84.2)$ & $10(5.6)$ & \multirow{2}{*}{230.22} & \multirow[b]{2}{*}{$\leq 0.0001$} \\
\hline & No & $28(15.8)$ & $167(94.4)$ & & \\
\hline \multirow{2}{*}{ Rhinorrhea } & Yes & $163(92.1)$ & $19(10.7)$ & \multirow{2}{*}{221.22} & \multirow[b]{2}{*}{$\leq 0.0001$} \\
\hline & No & $14(7.9)$ & $158(89.3)$ & & \\
\hline \multirow[b]{2}{*}{ Excessive Sneezing } & Yes & $162(91.5)$ & $9(5.1)$ & \multirow[b]{2}{*}{264.813} & \multirow[b]{2}{*}{$\leq 0.0001$} \\
\hline & No & $15(8.5)$ & $168(94.9)$ & & \\
\hline \multirow{2}{*}{ Nasal Itching } & Yes & $158(89.3)$ & $20(11.3)$ & \multirow[b]{2}{*}{224.419} & \multirow{2}{*}{$\leq 0.0001$} \\
\hline & No & $19(10.7)$ & $157(88.7)$ & & \\
\hline \multirow[b]{2}{*}{ Smelling } & Yes & $120(67.7)$ & $43(24.3)$ & \multirow{2}{*}{62.41} & \multirow[b]{2}{*}{$\leq 0.0001$} \\
\hline & No & $5732.3)$ & $134(75.7)$ & & \\
\hline \multirow{2}{*}{ Headache or facial pain } & Yes & $131(74.0)$ & $38(21.5)$ & \multirow{2}{*}{104.21} & \multirow{2}{*}{$\leq 0.0001$} \\
\hline & No & $46(26.0)$ & $139(78.5)$ & & \\
\hline \multirow[b]{2}{*}{ Nasal bleeding } & Yes & $12(6.8)$ & $29(16.4)$ & \multirow{2}{*}{10.41} & \multirow{2}{*}{$\leq 0.0001$} \\
\hline & No & $165(93.2)$ & $148(83.6)$ & & \\
\hline \multirow{2}{*}{ Symptoms Perennial } & Yes & $22(12.4)$ & $46(26.0)$ & \multirow{2}{*}{10.485} & \multirow{2}{*}{0.002} \\
\hline & No & $155(87.6)$ & $131(74.0)$ & & \\
\hline \multirow{2}{*}{ Symptoms Seasonal } & Yes & $156(88.1)$ & $43(24.3)$ & \multirow[b]{2}{*}{152.234} & \multirow{2}{*}{$\leq 0.0001$} \\
\hline & No & $21(11.9)$ & $134(75.7)$ & & \\
\hline
\end{tabular}




\section{Results}

Of the 360 school children recruited for this study, a total of 354 completed the study. Overall, 179 (50.6\%) males and 175 (49.4\%) females were involved. Two parents refused consent, for they felt that their children were not diseased and cannot be allowed to take part in the study. Two pupils did not want blood samples taken from them. The other two did not turn up with stool samples. Rhinorrhea was the most common symptom among the study population with 163 (92.1\%). This was closely followed by excessive sneezing 162 (91.5\%) while nasal itching, nasal congestion and headache and facial pain were noted in 158 (89.3\%), 149 (84.2\%) and 131 (74.0\%) respectively. There was a statistically significant difference in distribution of allergic rhinitis symptoms of study participants with a $\mathrm{p}$ value of $\leq 0.00001$ for each symptom. Furthermore, 156 (88.1\%) had seasonal symptoms ( $\mathrm{p}=\leq 0.00001)$ while $22(12.4 \%)$ were perennial with $\mathrm{p}=0.002$ as illustrated in Table 1 .
The distribution of impacts of symptoms on allergic rhinitis subjects is shown in Figure 1. Fifty - five percent (55\%) of the subjects had problem sleeping, while twenty - three percent (23\%) had problem playing or doing other activities. Also, twenty - two percent (22\%) experienced disruption in school. Out of the 177 subjects with allergic rhinitis recruited in 10 Government Primary Schools, 90 (51\%) had runny nose. This was followed by nasal congestion in $40(23 \%)$ of the subjects. Other documented symptoms in the study were excessive sneezing 25 (14\%) and nasal itching / itching eyes 22 (12\%) as illustrated in Figure 2. Triggers of allergic rhinitis in this study were mainly Dust (68\%). Then cold weather (60\%), family history of atopy (51\%), exposure to tobacco smoking (30\%) and the least was pets (25\%) Figure 3. The degree of allergic rhinitis symptoms was a statistically significant between the subjects and the controls Table 2 .

Table 2: Distribution of severity of allergic symptoms among subjects and controls.

\begin{tabular}{|c|c|c|c|c|c|c|}
\hline Symptom Severity & SubjectsN (\%) & ControlsN (\%) & Total & $\mathbf{X}^{2}$ & P-value & Remarks \\
\hline No symptom & $10(5.6)$ & $147(83.1)$ & 157 & \multirow{5}{*}{276.548} & \multirow{5}{*}{$\leq 0.0001$} & \multirow{5}{*}{ Using Fisher exact value } \\
\hline Mild & $15(8.5)$ & $30(16.9)$ & 45 & & & \\
\hline Moderate & $125(70.6)$ & 0 & 125 & & & \\
\hline Severe & 27 (15.3) & 0 & 27 & & & \\
\hline Total & 177 & 177 & 354 & & & \\
\hline
\end{tabular}

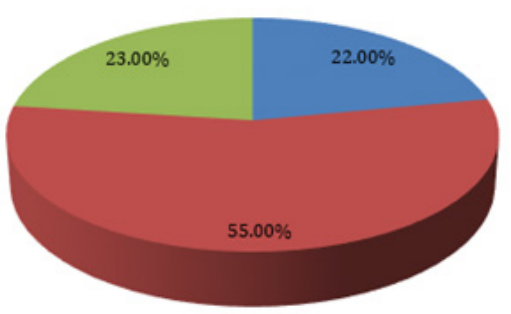

= Disruption in school $(\mathrm{N}=39)$

- Problem sleeping $(\mathrm{N}=98)$

= Problem playing or other activities $(N=40)$

Figure 1: Impacts of symptoms on allergic rhinitis subjects.

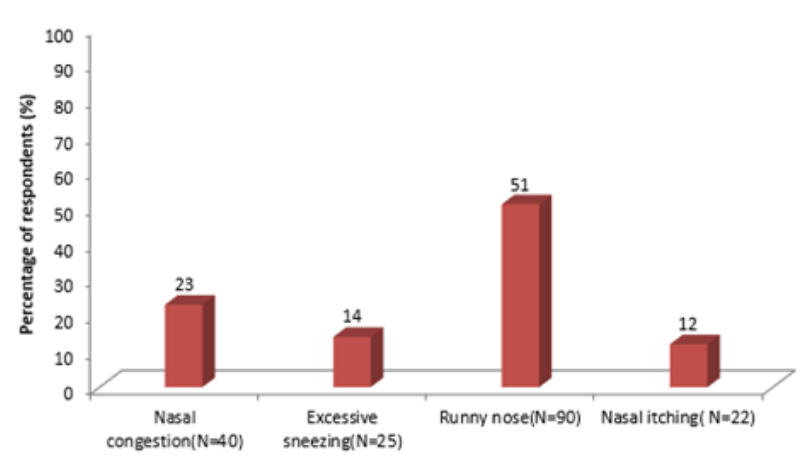

Figure 2: Distribution of most troublesome symptoms in allergic rhinitis subjects.

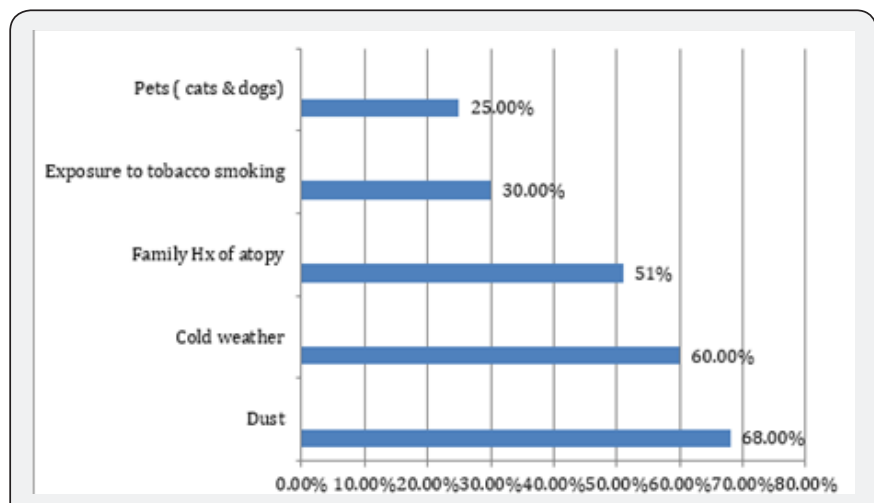

Figure 3: Triggers of allergic rhinitis in the participants.

\section{Discussion}

AR is most prevalent during school age, affecting up to $15 \%$ of 6-7-year-old and $40 \%$ of $14-15$-year-old [13]. It is a common clinical condition in children and is fundamentally supported by an inflammatory state [14]. AR is one of the common conditions that have considerable effects on the quality of life and significant consequences if left untreated [15]. Morbidity may result from associated conditions such as sinusitis, and otitis media with effusion [16]. The impact of AR is tremendous; its severity ranges from mild to seriously debilitating [17]. In children, there is evidence that symptoms of AR can impair cognitive functioning that can be further impaired by the firstgeneration antihistamines [2]. Sinusitis and asthma are the two 
most common co morbidities in children with allergic rhinitis. Studies showed that about $20 \%$ to $50 \%$ of asthmatic patients have AR [18]. Children with this condition tend to demonstrate shyness, depression, anxiety, fearfulness and fatigue, which can affect attentiveness and concentration at school [19]. Also, it has been documented that these wards when left untreated have an impairment of short-term memory and knowledge acquisition and application [20]. We reported 98 (55\%) with sleep disturbance. Green et al. [21] in South Africa in their study recorded $76.6 \%$ sleep challenge. Others impacts of the allergic rhinitis reported in our study population are $23.0 \%$ with interference with daily activities and playing or socialization and $22.0 \%$ of those with disruption in school attendance. This was in agreement with other studies in literature $[2,19,20]$.

The most common symptom in the study was rhinorrhea (runny nose) in the AR subjects with 163 (92.1\%) affected. This was followed by excessive sneezing in 162 (91.5\%) and nasal itching / itching eyes in 158 (89.3\%), each with a p - value of $\leq 0.0001$. This finding was similar to that of Patel et al. [11] who reported the presence of rhinorrhea in all his patients (100\%), followed by sneezing in $67(95.7 \%)$ and nasal blockage in 16 (22.86\%). Other investigators like Hedaiat et al. [22] reported rhinorrhoea (85\%) and nasal obstruction (65\%) as the most frequent symptoms of clinical allergic rhinitis observed. Similarly, Kumar et al. [ 5] in their study observed rhinorrhoea (100\%) followed by nasal obstruction (81\%).The most troublesome symptom among AR participants in our study was runny nose (rhinorrhoea) 90 (51\%), followed by nasal congestion (blockage) 40 (23\%), excessive sneezing 25 (14\%) and nasal itching / itching eyes 22 (12\%). The finding of increased runny nose (rhinorrhoea) apart from the allergic background may be in part due to viral and bacterial upper respiratory tract infections commonly seen in children.

Various risk factors of AR include environmental factors such as dust, high level of pollution, moulds, weather changes, pollens, pets, and exposure to tobacco smoke. In this study, we noticed that AR was precipitated by dust in $68 \%$. This was followed by cold weather (60\%) and strong family history of atopy (51\%). Kumar et al. [5]: dust and cold weather changes were allergens reported in $81 \%$ and $62 \%$ respectively. Also, Sonawane et al. [23] reported dust in 54 (87.1\%), weather changes 37 (59.7\%), history of family atopy $27(43.6 \%)$ and animal pets13 $(21.0 \%)$. Family history of atopy was a strong risk factor in this study like in Mercer et al. [16] who reported that family history was positive for AR in $88 \%$ of their patients. However, in sharp contrast to this study Mercer et al. [16] also reported that the most common allergens identified were pollen - tree pollen, and cat. Seasonal symptoms accounted for $88.1 \%$ in the AR subjects and $24.3 \%$ in the control group ( $p=\leq 0.0001$ ) while perennial symptoms were seen in $12.4 \%$ of the AR subjects and $26.0 \%$ in the controls $(p=0.002)$. There was a statistically significant association between seasonal symptoms and AR in the study.
This is comparable to other studies [22,24]. However, Mercer et al. [16] reported that rhinitis was chronic in $61.3 \%$, although $53.5 \%$ of their respondents reported seasonal variation. Also, Olusesi et al. [25] reported 59\% with perennial symptoms and $41 \%$ with seasonal symptoms.

\section{Conclusion}

The impacts of AR in school children were enormous, varying from sleep deprivation, social isolation and impaired daily activities, to absenteeism. The commonest identified precipitating factor was dust, while the most troublesome symptom was watery rhinorrhoea. We advocate avoidance of this allergen as first line of management.

\section{References}

1. Bousquet J, Khaltaev N, Cruz AA, Denburg J, Fokkens WJ, et al. (2008) Allergic rhinitis and its impact on asthma ARIA 2008 Update in Collaboration with World Health Organization, GA2LEN and Aller Gen. Allergy 63: 8-160.

2. Mir E, Panjabi C, Shah A (2012) Impact of allergic rhinitis in school going children. Asia Pac Allergy 2(2): 93-100.

3. Jauregui I, Mullol J, Davilla I, Ferrer M, Bartra J, del Curvillo A, et al. (2009) Allergic rhinitis and school performance. J Investig Allergol Clin Immunol 9(1): 32-39.

4. Nasiri R, Homagostar G, Tajik M, Shekari A, Roshani D, et al. (2015) Evaluation of prevalence of allergic rhinitis symptoms in Kurdistan, a Western province in Iran. Int. J Pediatr 3(23): 1039-1046.

5. Kumar N, Bylappa K, Ramesh AC, Ready S (2012) A study of eosinophil count in nasal and blood smear in allergic respiratory diseases in a rural setup. Internet J Med Update 7: 40-46.

6. Ahmadiafshar A, Taghiloo D, Esmailzadeh A, Falakaflaki B (2012) Nasal eosinophilia as a marker for allergic rhinitis: A controlled study of 50 patients. Ear Nose Throat J 91(3): 122-124.

7. Abhey S (2005) Diagnostic significance of nasal eosinophilia in allergic rhinitis. Indian J. Otolaryngol. Head Neck Surg 57(1): 13-16.

8. Rakesh C, Aggarwal KK, Kohli GS, Jaswal TS, Gupta KB (2002) Comparative study of nasal smear and biopsy in patients with allergic rhinitis. Indian J Allergy Asthma Immunol 16: 27-31.

9. Shioda H, Mishima T (1966) Significance of mast cells in nasal smears from patients with food allergy. J Allergy 37(6): 321-328.

10. Brito Babapulle F (2003) The eosinophilias, including the idiopathic hypereosinophilic syndrome. Br J Haematol 121(2): 203-23.

11. Patel AK, Nagpal TP (2014) Comparison of blood absolute eosinophil count and nasal smear eosinophilia with symptoms and severity of clinical score in patients of allergic rhinitis. Indian J Allergy Asthma Immunol 28(2): 74-77.

12. Chowdary VS, Vinaykumar EC, Rao JJ, Rao R, Rambabu K, et al. (2003) A study of serum. Ig E and eosinophils in respiratory allergy patients. Indian J Allergy Asthma Immunol 17: 21-24.

13. Skoner DP (2001) Allergic Rhinitis: Definition, Epidemiology, Pathophysiology, Detection and Diagnosis. J Allergy Clin Immunol 108(1): S2-8.

14. Powe DG, Huskinsson RS, Carney AS, Jekins D, Jones NS (2001) Evidence for an inflammatory pathophysiology in idiopathic rhinitis. Clin Exp Allergy 31(6): 864-872.

15. Nathan RA (2007) The burden of Allergic rhinitis. Allergy Asthma Proc 28 (1): 3-9. 
16. Mercer MJ, Van der Linde GP, Joubert G (2002) Rhinitis (allergic and non-allergic) in an atopic paediatric referral population in the grassland of inland South Africa. Ann Allergy Asthma Immunol 89(5): 503-512.

17. Schoenwetter WF, Dupclay LJ, Appajosyulla S, Botteman MF, Pasho CL (2004) Economic impact and quality of life burden of allergic rhinitis. Curr Med Res Opin 20(3): 305-317.

18. Linneberg A, Henrik Nielsen N, Frolund L, Madsen F, Dirksen A, et al. (2002) The link between allergic rhinitis and allergic asthma: a prospective population - based study. The Copenhagen Allergy Study. Allergy 57(11): 1048-1502.

19. Blender BG (1992) Learning disorders associated with asthma and allergies. School Psychol Rev 28(2): 204-214.

20. Blaiss M (2004) Allergic rhinitis and impairment issues in school children. A consensus reports. Curr Med Res Opin 20(12): 19371952.

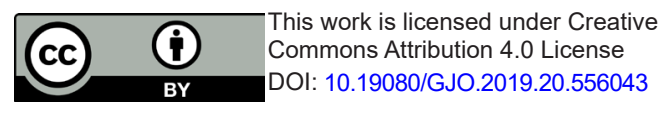

21. Green RJ, Davis G, Price D (2007) Concerns of patients with allergic rhinitis: the allergic rhinitis care programme in South Africa. Prim Care Respir J 16(5): 299-303.

22. Hedaiat A, Hosseini RF, Miri S, Amin R (2004) The prevalence of allergic rhinitis among 11-15 years old children in Shiraz. Iran J Immumol 1: 133-137.

23. Sonwane R, Ahire N, Patil S, Korde A (2016) Study of eosinophil count in nasal and blood smear in allergic respiratory diseases. MVP J Med Sci 3(1): 44-51.

24. Provero MC, Macchi A, Antognazza S, Marinoni M, Nespoli L (2013) Allergic and nonallergic rhinitis in children: The role of nasal cytology. Open J Pediatr 3: 133-138.

25. Olusesi AD, Said MA, Amodu EJ (2007) A correlation of Symptomatology with nasal smear eosinophilia in non-infectious chronic rhinitis: Preliminary report. Niger J Clin Pract 10(3): 238242.

\section{Your next submission with Juniper Publishers will reach you the below assets}

- Quality Editorial service

- Swift Peer Review

- Reprints availability

- E-prints Service

- Manuscript Podcast for convenient understanding

- Global attainment for your research

- Manuscript accessibility in different formats ( Pdf, E-pub, Full Text, Audio)

- Unceasing customer service

Track the below URL for one-step submission https://juniperpublishers.com/online-submission.php 